\title{
Questioning the developmental effects of group size on cognitive abilities
}

\author{
Connor T. Lambert ${ }^{1} \cdot$ Kendra B. Sewall ${ }^{2} \cdot$ Lauren M. Guillette ${ }^{1,3}$ (D)
}

Published online: 20 November 2019

(C) The Psychonomic Society, Inc. 2019

\begin{abstract}
Australian magpies living in larger social groups learned quicker and made fewer errors across four cognitive tasks compared with birds living in smaller social groups, and this pattern may be driven by a developmental effect associated with the cognitive demands of living in larger groups. While Smulders (2018, Learning and Behavior, 1-2, doi:10.3758/s13420-018-0335-0) questioned whether this group size-cognitive performance pattern was driven by motivation rather than cognitive abilities, we question whether there is truly evidence of a developmental effect and whether the relationship between group size and cognitive performance can be explained in other ways. We highlight potential alternative explanations for the relationship between group size and cognitive performance and highlight some of the theoretical issues underlying the developmental effects of group size on cognitive abilities.
\end{abstract}

Keywords Cognitive ecology $\cdot$ Comparative cognition $\cdot$ Social learning

Ashton, Ridley, Edwards, and Thornton (2018a) aimed to test how the demands of social living select for enhanced cognition, known as the social intelligence hypothesis, within a single species by examining the relationship between social group size and cognitive abilities in wild Australian magpies (Cracticus tibicen dorsalis). They found that adults from larger social groups learned more quickly and made fewer errors across four cognitive tasks (inhibitory control, associative learning, reversal learning, and spatial memory) compared with adults from smaller social groups. The correlations between group size and cognitive performance are robust: Group size was the best predictor of performance for each of the four tasks independently, as well as the first principal component of general cognitive performance (representing a combined score of all four tasks). The authors interpret this correlation as evidence that the demands of sociality drive enhanced cognition. Then, in a second

Lauren M. Guillette

guillett@ualberta.ca

1 Department of Psychology, University of Alberta, Edmonton, Canada

2 Department of Biological Sciences and School of Neuroscience, Virginia Tech, Blacksburg, VA, USA

3 School of Biology, University of St Andrews, St Andrews, UK experiment, Ashton, Ridley, Edwards, et al. (2018a) endeavor to examine why these cognitive differences exist, specifically, by testing if these cognitive differences emerge over developmental time. The authors argue that if cognitive differences are not initially related to group size in young birds, but this relationship emerges over time, then increased "information processing demands" (p. 364) that result from living in a larger social group (and interacting with more individuals) may drive cognitive development. To answer this question, the authors tested the same juvenile magpies at 100 (when the birds reach nutritional independence), 200, and again at 300 days postfledge. Ashton, Ridley, Edwards, et al. (2018a) found positive correlations between general cognitive performance and group size in 200 and 300 days postfledge magpies that was not apparent in the same birds at 100 days postfledge. Thus, it was concluded that group size interacts with development to affect cognitive performance.

Smulders (2018) suggests that the relationship between social group size and cognitive performance could be driven by motivation: Birds living in larger groups may be more foodmotivated than birds in smaller groups, leading to increased focus and thus "better" performance on the cognitive tasks. In their response, Ashton, Ridley, and Thornton (2018b) provide evidence against the role of motivation. For example, birds that are more food motivated should (1) interact more quickly with the learning tasks because each provided food rewards, 
and/or (2) spend more time interacting with the learning tasks in an effort to obtain more food. However, the general cognitive performance of adult magpies was not associated with either of these measures of motivation. In fact, potential confounding factors, such a motivation to feed, highlight just one of the difficulties of studying cognitive abilities, particularly in the wild, and demonstrate the outstanding contribution of Ashton (2018a; Griffin, Guillette, \& Healy, 2015; MorandFerron, Cole, \& Quinn, 2016; Rowe \& Healy, 2014).

Here, we argue that these developmental data, especially from birds age 100 days postfledge, are less robust than results obtained for the adults and call into question the developmental effect as a mechanism resulting in adults from large social groups being smarter. We then briefly consider other potential factors that could contribute to adults in larger social groups performing better on cognitive tasks than individuals from smaller social groups. Lastly, we question the underlying theory linking group size, cognitive processes, and cognitive development and suggest future directions to examine (1) whether living in larger groups does indeed result in increased information processing demands, and (2) whether and how the source (i.e., asocial vs. social) of to-be-processed information matters in terms of development of cognitive abilities.

\section{Dearth of data across development}

\section{Cognitive tests at 100 days postfledge}

A distinct strength of the work by Ashton et al. (2018a) is that they examined animals' cognition in their natural social and ecological environment to better understand cognitive evolution. These studies represent a tremendous and timely effort to examine individual variation and development of cognitive abilities and fitness in wild animals. The nature of this work, however, raises several concerns. The first is the (over) interpretation of results from juveniles at 100 days postfledgenamely, there are not enough data to conclude the lack of relationship between general cognitive performance and social group size. Of the four cognitive tasks (inhibitory control, associative learning, reversal learning, and spatial memory), two of them (associative learning and reversal learning) were not successfully completed by any of the 100 days postfledge birds. Moreover, more than half of these birds (12/21) failed to reach criterion in the inhibitory control task, and six of 20 individuals failed to search above chance in the spatial memory task. Thus, we are left with limited data from two (inhibitory control and spatial memory) of the four cognitive tasks that were completed by these same individuals at 200 and 300 days postfledge and all adults. Without robust evidence that general cognition was not correlated with group size at nutritional independence, the conclusion that cognition developed in response to social pressures is not substantiated.

\section{Cognitive tests at 200 and 300 days postfledge}

The positive correlations reported for magpies at 200 (see Fig. $3 \mathrm{a}$ in Ashton et al., 2018a; $n=13$ ) and 300 days postfledge (see Fig. 3 b in Ashton et al., 2018a; $n=10$ ) are driven by two birds: one individual from the smallest social group (of two) and another individual from the largest social group (of 12; as measured by Cook's distance and DFBETA; Belsley, Kuh, \& Welsch, 1980; Cook, 1977). Removal of these two individuals results in nonsignificant negative correlation between social group size and general cognitive performance, meaning group size did not significantly relate to general cognitive performance. Given this dearth of data, we suggest it is difficult to conclude whether social group size does or does not relate to cognitive performance in young birds across development, compared with the robust positive correlations reported for adults $(n=46)$.

\section{What is driving the relationship between social group size and cognitive performance in adults?}

\section{Timing of potential developmental effect}

Ashton et al. (2018a) propose that important cognitive development occurs in a developmental time window after 100 days postfledge, once birds begin foraging independently. Behaviors such as song learning (Beecher \& Brenowitz, 2005), kin recognition (Gerlach, Hodgins-Davis, Avolio, \& Schunter, 2008), and maternal and sexual imprinting (Bolhuis, 1991) have specific development windows in some species. Additionally, spatial memory may have developmental windows (Roth \& Krochmal, 2015) or be highly plastic even in maturity depending on the species (Buchanan, Grindstaff, \& Pravosudov, 2013). However, the timing of the development of other cognitive abilities, namely those tested by Ashton et al. (2018a) requires further study. If the relationship between cognitive performance and group size is not explained by a developmental effect, this leaves open a few alternative explanations.

\section{Heritability/social learning}

In humans, heritability of general cognitive ability can be upwards of $60 \%$ in adulthood (Croston, Branch, Kozlovsky, Dukas, \& Pravosudov, 2015; Plomin \& Deary, 2015), and in nonhuman animals heritability of performance on different cognitive tasks ranges from more than $20 \%$ in mice (Mus musculus; Sauce et al., 2018) to more than 50\% in chimpanzees (Pan troglodytes; Croston et al., 2015). Given that the mating patterns of this Australian magpie population and the fathers of the tested juveniles were unknown, and that no comparison is made between juveniles and their mothers' task performance, it seems difficult to exclude the role of 
heritability (genetic or cultural) in explaining the observed patterns of group size and cognitive performance.

Heritability could be genetic, or mothers may have behavioral traits that are socially learned or otherwise influence their offspring's cognitive development and performance (Aplin, 2018; Fleming et al., 2002; Whiten, 2019). It is essential to examine how much of the variability in observed cognitive performance is explained by heritability in order to distinguish the potential development effects of group size (Croston et al., 2015), which could be (partially) done in this study population by correlating the performance of females with their known offspring. If such a correlation was found, then cognitive performance may be genetically inherited or socially passed on by the mother.

Other potential explanations linked to heritability that were not tested include that increased cognitive performance leads to larger groups, that larger groups select for smarter birds, or that assortative grouping occurs. Ashton et al. (2018a) claim that larger groups are not the result of "females with increased cognitive performance produc[ing] large numbers of cognitively adept offspring" (p. 366) because magpie social groups in their study are highly stable and have high extragroup paternity. However, high group stability would seemingly support, not counter, the idea that smart females' reproductive success drives group size; if birds do not move among groups, then over time females that have higher reproductive success would lead to larger groups, and (assuming heritability) result in the observed link between group size and cognitive ability. Additionally, if larger groups do indeed have "higher information processing challenges," then it is possible that smarter individuals have better comparative survival in such groups than lower performing individuals. Finally, though the authors have observed no movement between groups during their entire study of this population (see the Methods section, pp. 1-2), if offspring do eventually disperse, then do they settle into established groups or form new groups, and how do they choose the group they settle in?

Ashton et al. (2018a) made good efforts to address and rule out potential contributions of neophobia, body size, and foraging ability as alternative explanations for the relationship between cognition and group size. The next exciting and important step for this work, and indeed the field, is to explicitly test alternative hypotheses about the evolutionary and developmental origins of individual variation in cognition: While these data raise the exciting hypothesis that cognition is driven by developmental processes, the authors rightly point out that only experimental manipulations of group size can support this conclusion.

\section{Theory linking group size and cognitive development}

Lastly, we wish to consider the theoretical backdrop in which the link between individual differences in cognition and social group size is framed. While the evidence for a developmental effect of group size on cognitive abilities in Ashton et al. (2018a) is uncertain, the theory explaining this relationship is equally unclear. The social intelligence (or social brain) hypothesis was originally proposed as a hypothesis to explain the evolution of cognitive abilities and brain size among species of primates (Dunbar, 1998; Humphrey, 1976; Jolly, 1966). The social intelligence hypothesis specifically suggests that the cognitive demands of group living and maintaining social relationships act as selective forces that, over evolutionary time, select for faster learning and other cognitive abilities that also result in associated changes to various brain metrics (Ashton, Thornton, \& Ridley, 2018c; Dunbar, 1998). However, why the social intelligence hypothesis translates to the impact of the social environment on individual differences in cognitive abilities over developmental time is uncertain. The social intelligence hypothesis posits nothing about the effects of group living over developmental time, only the effects of group living over evolutionary time. Ashton, Thornton, et al. (2018c) recently summarized the social intelligence hypothesis and its extension to individual differences in cognition, and it is of note that there have been a limited number of studies experimentally examining the effects of living in larger groups on cognitive abilities (Croney \& Newberry, 2007; Sewall, 2015). While studies examining social deprivation (e.g., isolation experiments) seem to consistently find reduced learning abilities in isolated individuals (Kosten, Kim, \& Lee, 2012), how and why natural variation in social environments impacts individual cognitive abilities deserves further attention, especially in regard to why social features might affect (asocial) learning abilities.

Ashton et al. (2018a) point out that the strongest evidence for the social intelligence hypothesis in studies across species is that clear differences in social challenges among species have been correlated with cognitive outcomes. A critical gap in their present study of intraspecific variation in group size and cognition is defining how cognitive demands differ with group size. The proposed mechanism of heightened information processing from group living may be important in cognitive development, and relates to many studies that have examined the effects of "enriched" environments on cognition and the notion of experience-dependent plasticity in neural development and growth (Greenough, Black, \& Wallace, 1987; Mercado, 2011). Still, we are left with many questions regarding the theory underlying social (and asocial) environmental effects on cognitive abilities: Is information processing a valid mechanism influencing cognitive abilities? If so, what sort of information is predicted to affect cognitive abilities, and why? How would such information processing vary among group sizes that range from three to 12 individuals? Are there other, aspects of group living that are more important for cognitive development, such as number and strength of social connections? Are such effects expected to be consistent within and among species? While many questions remain, key among 
them is, Does living in a larger group necessitate increased information processing?

Further investigation of the impact of the social environment on cognitive abilities and their underlying mechanisms is needed, along with systematic review of evidence that is already available. In order to best understand how the social environment influences cognition - or whether it even does at all —it is essential that, as mentioned by Ashton et al. (2018a), controlled experiments built on theory examine social factors and their effects on cognition and their associated neural mechanisms. Such experiments must rigorously test and account for other potential hypotheses, including the effects of motivation as mentioned by Smulders (2018) and parse out environmental and heritable factors. We applaud the work of Ashton et al. (2018a) and urge future emphasis on determining what and why different environmental features impact cognitive abilities.

Acknowledgements This work was supported by the Natural Sciences and Engineering Council of Canada (NSERC), the Department of Psychology at the University of Alberta, and a Start-up Grant from the Faculty of Science at the University of Alberta.

\section{References}

Aplin, L. M. (2018). Culture and cultural evolution in birds: a review of the evidence. Animal Behaviour, 147, 179-187. doi:https://doi.org/ 10.1016/j.anbehav.2018.05.001

Ashton, B. J., Ridley, A. R., Edwards, E. K., \& Thornton, A. (2018a). Cognitive performance is linked to group size and affects fitness in Australian magpies. Nature, 554, 364-367. doi:https://doi.org/10. 1038/nature25503

Ashton, B. J., Ridley, A. R., \& Thornton, A. (2018b). Smarter through group living: A response to Smulders. Learning \& Behavior, 1-3. doi:https://doi.org/10.3758/s13420-018-0366-6

Ashton, B. J., Thornton, A., \& Ridley, A. R. (2018c). An intraspecific appraisal of the social intelligence hypothesis. Philosophical Transactions of the Royal Society B, 373. doi:https://doi.org/10. 1098/rstb.2017.0288

Beecher, M. D., \& Brenowitz, E. A. (2005). Functional aspects of song learning in songbirds. Trends in Ecology and Evolution, 20, 143149. doi:https://doi.org/10.1016/j.tree.2005.01.004

Belsley, D. A., Kuh, E., \& Welsch, R. E. (1980). Regression diagnostics: Identifying influential data and sources of collinearity. New York, NY: Wiley. doi:https://doi.org/10.1002/0471725153.ch2

Bolhuis, J. J. (1991). Mechanisms of Avian imprinting: A review. Biological Reviews of the Cambridge Philosophical Society, 66, 303-345.

Buchanan, K. L., Grindstaff, J. L., \& Pravosudov, V. V. (2013). Condition dependence, developmental plasticity, and cognition: Implications for ecology and evolution. Trends in Ecology and Evolution, 28, 290-296. doi:https://doi.org/10.1016/j.tree.2013.02.004

Cook, R. D. (1977). Detection of influential observation in linear regression. Technometrics, 19, 15-18. doi:https://doi.org/10.1080/ 00401706.1977 .10489493

Croney, C. C., \& Newberry, R. C. (2007). Group size and cognitive processes. Applied Animal Behaviour Science, 103, 215-228. doi: https://doi.org/10.1016/j.applanim.2006.05.023

Croston, R., Branch, C. L., Kozlovsky, D. Y., Dukas, R., \& Pravosudov, V. V. (2015). Heritability and the evolution of cognitive traits.
Behavioral Ecology, 26, 1447-1459. doi:https://doi.org/10.1093/ beheco/arv088

Dunbar, R. I. M. (1998). The social brain hypothesis. Evolutionary Anthropology: Issues, News, and Reviews, 5, 69. doi:https://doi. org/10.1093/acprof

Fleming, A. S., Kraemer, G. W., Gonzalez, A., Lovic, V., Rees, S., \& Melo, A. (2002). Mothering begets mothering: The transmission of behavior and its neurobiology across generations. Pharmacology Biochemistry and Behavior, 73, 61-75. doi:https://doi.org/10. 1016/S0091-3057(02)00793-1

Gerlach, G., Hodgins-Davis, A., Avolio, C., \& Schunter, C. (2008). Kin recognition in zebrafish: A 24-hour window for olfactory imprinting. Proceedings of the Royal Society B: Biological Sciences, 275, 2165-2170. doi:https://doi.org/10.1098/rspb.2008.0647

Greenough, W. T., Black, J. E., \& Wallace, C. S. (1987). Experience and brain development. Child Development, 58, 539-559. doi:https:// doi.org/10.2307/1130197

Griffin, A. S., Guillette, L. M., \& Healy, S. D. (2015). Cognition and personality: An analysis of an emerging field. Trends in Ecology and Evolution, 30, 207-214. doi:https://doi.org/10.1016/j.tree. 2015.01.012

Humphrey, N. K. (1976). The social function of intellect. In P. Bateson \& R. Hinde (Eds.), Growing points in ethology (pp. 303-317). Cambridge, England: Cambridge University Press.

Jolly, A. (1966). Lemur social behavior and primate intelligence. Science, 153, 501-506. doi:https://doi.org/10.1126/science.153.3735.501

Kosten, T. A., Kim, J. J., \& Lee, H. J. (2012). Early life manipulations alter learning and memory in rats. Neuroscience and Biobehavioral Reviews, 36, 1985-2006. doi:https://doi.org/10.1016/j.neubiorev. 2012.07 .003

Mercado, E., III. (2011). Mapping individual variations in learning capacity. International Journal of Comparative Psychology, 24, 4-35. doi:https://doi.org/10.1016/j.jebdp.2005.01.011

Morand-Ferron, J., Cole, E. F., \& Quinn, J. L. (2016). Studying the evolutionary ecology of cognition in the wild: A review of practical and conceptual challenges. Biological Reviews, 91, 367-389. doi: https://doi.org/10.1111/brv.12174

Plomin, R., \& Deary, I. J. (2015). Genetics and intelligence differences: Five special findings. Molecular Psychiatry, 20, 98-108. doi:https:// doi.org/10.1038/mp.2014.105

Roth, T. C., \& Krochmal, A. R. (2015). The role of age-specific learning and experience for turtles navigating a changing landscape. Current Biology, 25, 333-337. doi:https://doi.org/10.1016/j.cub.2014.11. 048

Rowe, C., \& Healy, S. D. (2014). Measuring variation in cognition. Behavioral Ecology, 25, 1287-1292. doi:https://doi.org/10.1093/ beheco/aru090

Sauce, B., Bendrath, S., Herzfeld, M., Siegel, D., Style, C., Rab, S., . . . Matzel, L. D. (2018). The impact of environmental interventions among mouse siblings on the heritability and malleability of general cognitive ability. Philosophical Transactions of the Royal Society B, 373. doi:https://doi.org/10.1098/rstb.2017.0289

Sewall, K. B. (2015). Social complexity as a driver of communication and cognition. Integrative and Comparative Biology, 55, 384-395. doi: https://doi.org/10.1093/icb/icv064

Smulders, T. V. (2018). Smarter through group living? Learning and Behavior, 1-2. doi:https://doi.org/10.3758/s13420-018-0335-0

Whiten, A. (2019). Cultural evolution in animals. Annual Review of Ecology, Evolution, and Systematics, 50, 1-22. doi:https://doi.org/ 10.1146/annurev-ecolsys-110218-025040

Publisher's note Springer Nature remains neutral with regard to jurisdictional claims in published maps and institutional affiliations. 